\title{
Immobilization Effect of Traditional Contraceptive Plants on Human Sperm
}

\author{
Kadam A.B. ${ }^{1 *}$, Gaykar B.M. ${ }^{2}$ \\ ${ }^{1}$ Department of Botany, New Arts, Com \& Sci. College, Ahmednagar \\ ${ }^{2}$ Department of Botany, Ahmednagar College, Ahmednagar
}

\begin{abstract}
Address for
Correspondance

Kadam A.B.,

ashakadam16@g

mail.com;

$\underline{\text { balasahebgaykar4 }}$

@.gmail.com

Received:

28.01.2017

Accepted:

28.05.2017

ABSTRACT: The aim of the present study is to support the ethno botanical knowledge of contraception with evidence by evaluating the activity of aqueous seed extracts of selected traditional contraceptive plant species. In this study, effect of extracts on human sperm motility was examined under in vitro using human sperm sample. Aqueous extract of Moringa oleifera L., Crotolaria juncea L., Sapindus trifoliatus L., Trigonella foenum-graecum L. and Ricinus communis L. seeds was used to treat fresh human semen in 1:1 volumetric ratio. The motility of sperm was noted under a compound microscope at the interval of 15 seconds. Morphological changes were also noted simultaneously. The sperm immobilization effects of the seed extract appeared immediately when the semen samples were treated with aqueous extracts. The sperms treated with Moringa oleifera L. and Sapindus trifoliatus L. extracts, $100 \%$ sperms completely lost their motility within a minute. The findings of these study reported that aqueous seed extract of Moringa oleifera L. and Sapindus trifoliatus L. showed inhibition of sperm motility, which can be promising as a new male spermicidal contraceptives. (C) 2018 iGlobal Research and Publishing Foundation. All rights reserved.
\end{abstract}

Keywords Traditional Contraceptive Plants; Spermicidal; Human Sperm Motility.

\section{INTRODUCTION}

Contraception means prevention of pregnancy, which is a worldwide interesting matter of concept and investigation. About $90 \%$ of the World's contraceptive users are women. Contraceptives an effective birth control measure, which uses in recent time as high rate. But male contraceptives are less successful than that of female ones [1]. However, when one looks at the contraceptive choices available in the market, the balance is tilted in favor of women. Condoms and vasectomy are the two methods of contraception easily available for men at present. [2]. Male contraceptive activity is related with Sperm mobility. It describes the ability of sperm to move properly towards an egg. The healthy sperms and motility plays an important role in successful pregnancies. Improper movement and arrest the sperms by natural spermicides are one of the important contraceptive for males. Recently, attention towards spermicidal activity has become more positive as pregnancy barrier. Even the World Health Organization formed coalitions with governments and international agencies to support research and activities in this field [3]. Several plant products inhibit male and female fertility and may be developed into contraceptives. Since the last decade, efforts have been made to work on spermicidal agents. Herbal preparations have been tested for spermicidal action in a number of countries [4]. Effects of some plants like Gossypium herbaceum [5], Azadirachta indica [6,7], Tripterygium wilfordii [8], Echiveria gibbiflora [9,10], Allium sativum [11], Carica papaya [12], Alstonia macrophylla [13], Ricinus communis [14], Achyranthes aspera and Stephania hernandifolia [15] on human or animal sperm. A dosedependent and time-dependent effect of ethanol extract of Dalbergia sissoo Roxb. Stem Bark on sperm motility and sperm viability was observed [16]. 
Indo Global Journal of Pharmaceutical Sciences, 2018; 8(1): 21-25

Earlier studies have shown that the M. oleifera seeds have been used traditionally as an abortifacient $[17,18,19]$. The root of $M$. oleifera were shown to possess antifertility, antiinflammatory and act as a cardiac or circulatory tonic, used as an abortifacient, treating kidney pain [20]. In vitro studies on Sapindus saponaria proved that it has viginal spermicidal activity [21]. Aqueous stem bark extract of Riccinus communis L showed dose dependent loss of sperm motility by influencing the morphological deformation of spermatozoa [22]. Even though many indigenous plants have been shown to prevent birth, only few plants have so far been investigated for their anti-fertility activity [23, 24]. There are still some more indigenous traditional contraceptive plants which are not yet studied with respect to spemicidal activity. However, studies using the aqueous extract of Moringa seeds for testing the motility of human sperms have not yet been reported. Also the plants were not evaluated for contraceptive activity. Thus there is an urgent need of evaluation of biological contraceptives, which are safe and cost effective. In this article, we have tried to find out hormonal and non-hormonal methods of contraception for men. Therefore, the present work was undertaken to study effect of traditional contraceptive plants on human sperm motility under in vitro condition.

\section{MATERIALS AND METHODS}

\section{Chemicals}

Eosin Y (1\% solution in distilled water) and nigrosin $(10 \%$ solution in distilled water) were of analytical grade and obtained from Loba Chemicals.

\section{Plant material}

On the basis of literature [25] and survey of tribal people, following plants were selected for the scientific study of spermicidal activity. The selected plants were Moringa oleifera Linn. (Moringaceae), Crotalaria juncea L., (Fabaceae), Trigonalla foenum-graecum L(Fabaceae). Sapindus trifoliatus L. (Sapindaceae), Ricinus communis L. (Euphorbiaceae).

Fresh Seeds were harvested from their natural habitat. Plant Samples were collected from various areas of Ahmednagar District, India and were identified from Botanical Survey of India, Western Circle, Pune. The voucher specimens were deposited in the Herbarium, BSI, Pune as well as Herbarium of Department of Botany, New Arts, Commerce and Science College, Ahmednagar.(ABK 001,ABK 002,ABK 003,ABK 004,ABK 005).

\section{Preparation of plant extract}

The plant materials were shade dried, powdered and subjected to Soxhelet extraction with distilled water. The extract was evaporated to dryness in a rotary vaccume evaporator at $40^{\circ} \mathrm{C}$ to yield plant extract. Stock solution of the extract $(10 \mathrm{mg} / \mathrm{ml})$ was prepared in normal saline for in vitro studies.

\section{Preparation of sperm suspension}

Semen was collected from human male volunteers. Semen samples were collected in a room near the laboratory obtained from men by self-masturbation. The experiment was performed with spermatozoa from apparently normal, healthy men who had either fathered children or had never attempted to procreate, and whose ejaculates appeared normal in all aspects [26]. The semen sample was diluted with normal saline and stored at $37^{\circ} \mathrm{C}$ in an incubator for half an hour. For analyses, semen samples were allowed to liquefy at room temperature and seminal volume, $\mathrm{pH}$, sperm count, motility and morphology were analyzed according to guidelines [27].

\section{Immobilization assay}

To test the efficacy of individual plant extract, $10 \mu \mathrm{l}$ of sperm suspension and $10 \mu \mathrm{l}$ of plant extract (1:1) were placed on a glass slide and mixed uniformly. Physiological saline solution $(\mathrm{pH}$ 7.4), was mixed at a ratio of $1: 1$ with the sperm suspension used as a control. A drop of the mixture was immediately placed on the glass slide, stained by a drop of eosin solution (Loba Chem) and covered with a cover slip.

Sperm Motility: Sperm motility was noted following the Sander-Cramer method [28, 29]. Wet drop technique was applied to study the motility of spermatozoa [30]. The microscope field was examined systematically for assessing the sperm motility. The sperm motility was seen at various time intervals starting from $0 \mathrm{sec}$ and once in every $15 \mathrm{sec}$, up to $90 \mathrm{sec}$. Sperm motility was determined by counting all motile and non motile spermatozoa in several randomly chosen fields other than fields near by cover slip using a 40x objective. Only free spermatozoa were assessed. Abnormal sperm were not counted. Approximately 200 sperms were observed and classified according to their motility on the basis of percentage. The percentage motility per sample was calculated based on the following formula:

Mobility $=$ Mobile sperm/Motile + non motile sperms x100

\section{Sperm viability test}

Sperms were mixed with seed extract separately for $20 \mathrm{~s}$. Sperm viability was checked using Eosin- Nigrosin (Loba Chem) technique. One drop of above treated sperm mixed with 2 drops $1 \%$ EosinY. After 30 s, 3 drops of $10 \%$ of Nigrosin solution was added. A drop of treated sperm-Eosin- 
Indo Global Journal of Pharmaceutical Sciences, 2018; 8(1): 21-25

Nigrosin mixture is placed on a clear microscope slide; allowed to dry and observed under microscope. Unstained spermatozoa were counted as live and stained were counted as dead spermatozoa [31].

\section{Sperm Morphology}

Sperm morphology of treated sperm was studied under the microscope using EosinY and Nigrosin staining method as described above. A drop of sperm- eosin-nigrosin mixture treated with selected plants seed extract was examined separately at 40X under compound microscope to record any change in morphology of the sperm [32].

\section{RESULTS AND DISCUSSION}

The effect of aqueous extracts of Moringa oleifera Linn. , Crotalaria juncea L., Trigonalla foenum-graecum L., Sapindus trifoliatus L. and Ricinus communis L. seeds on the motility of sperms and the results are presented in Table 1. The results are the proportion of motile spermatozoa, expressed as an integer percentage. It was observed that motility percentage was decreased as time of incubation increased. In Moringa and Sapindus extract the motility was arrested immediately within first 15 seconds and the sperms loosed viability. The plants (Crotalaria juncea L., Trigonalla foenum-graecum L., and Ricinus communis L.) have shown time-dependent effect of aqueous extract of seeds on sperm motility and sperm viability. The findings of the present study clearly indicate that the aqueous extracts also have an effect on the motility of the human sperms and points to the prospective of the use as male contraceptive, which deserves further investigation.

Moringa oleifera (Linn) is a medicinally important plant, belonging to family Moringaceae. The plant is also well recognized in India, Pakistan, Bangladesh and Afghanistan as a folkloric medicine [33]. The seeds have been used in indigenous medicine for over many decades. Aqueous leaf extract of Moringa oleifera may increase sperm count at high dose and may not improve the percentage of normal sperm cells in male albino wistar rats. [34]. In the present results, the sperm mobility was $84 \pm 1.6 \%$ as observed in control. They become immotile within next 15 seconds with the treatment of aqueous extract of Moringa seeds. There was increased amount of non motile sperms. This can be termed as Asthenospemia. No morphological changes were found in the sperm head, mid-piece and tail when compared with control. Immobilization of sperm may be due to blockage of some biochemical pathway like energy utilization, which would require further investigation. The results showed potent spermicidal activity for Moringa oleifera L. seed extract. Therefore, chronic consumption of M. oleifera may not improve fertility in males. The present work was carried out by using human sperm and the results obtained were significant.

Sapindus trifoliatus $\mathrm{L}$ is tree, abruptly pinnate, fruits fleshy and seeds blackish. It is commonly called Indian soapberry. It is used traditionally to cure ulcers, external wounds and inflammation. It was revealed that complimentary in vivo studies of Sapindus saponaria L. seeds should be made for establish the use as a viginal spermicidal, particularly in Brazil and Latin America [21]. Similar results were obtained in the aqueous extract of Sapindus trifoliatus L seeds. Similarly like Moringa, no morphological changes were found in the sperm head, mid-piece and tail when compared with untreated sperm. Therefore, $100 \%$ killing of sperm may be due presence of oleanolic and oleic acid [35]. Oleanolic acid administration for 30 days was adequate to produce reversible sterility in male Wistar rats, without adverse effects on libido [36].

Table1. In vitro effect of aqueous extracts of seeds on human sperm motility.

\begin{tabular}{|cccccccc|}
\hline & \multicolumn{6}{c}{ Percent motility of spermatozoa at different time intervals (seconds) } \\
\hline & 0 & 15 & 30 & 45 & 60 & 75 & 90 \\
\hline Control & $83 \pm 1.6$ & $83 \pm 1.6$ & $83 \pm 1.6$ & $82 \pm 1.6$ & $83 \pm 1.6$ & $81 \pm 2.4$ & $81 \pm 2.4$ \\
\hline $\begin{array}{c}\text { Moringa } \\
\text { oleifera } \mathbf{L} \text {. }\end{array}$ & $83 \pm 1.6$ & 00 & 00 & 00 & 00 & 00 & 00 \\
\hline $\begin{array}{c}\text { Crotolaria } \\
\text { juncea } \text { L. }\end{array}$ & $83 \pm 1.6$ & $63 \pm 1.3$ & $63 \pm 1.3$ & $56 \pm 1.2$ & $42 \pm 2.1$ & $21 \pm 1.2$ & 00 \\
\hline $\begin{array}{c}\text { Trigonella } \\
\text { foenum- } \\
\text { graecum } \text { L. }\end{array}$ & $83 \pm 1.6$ & $63 \pm 1.3$ & $63 \pm 1.3$ & $21 \pm 1.2$ & $21 \pm 1.2$ & 00 & 00 \\
\hline $\begin{array}{c}\text { Sapindus } \\
\text { trifoliatus } \mathbf{L} \text {. }\end{array}$ & $83 \pm 1.6$ & $\mathbf{0 0}$ & 00 & 00 & 00 & 00 & 00 \\
\hline $\begin{array}{c}\text { Ricinus } \\
\text { communis L. }\end{array}$ & $83 \pm 1.6$ & $63 \pm 1.3$ & $56 \pm 1.2$ & $21 \pm 1.2$ & 00 & 00 & 00 \\
\hline
\end{tabular}

Data shown are averages calculated from three experimental repeats. Values are mean $\pm \mathrm{SE}$ 


\section{Indo Global Journal of Pharmaceutical Sciences, 2018; 8(1): 21-25}

In this study hyper activation appears to occur prematurely in the treated group as compared to the control, suggesting that oleanolic and oleic acid might have altered the protein coat of the sperm and thus exposed the receptors. This is apparently the basis for acid's effect on sperm motility. Saponin isolated from Sapindus mukorossi has potent spermicidal activity. Morphological changes in human ejaculated spermatozoa after exposure to this saponin were evaluated under scanning electron microscopy. However, incubation of spermatozoa for 10 minutes resulted in extensive vesiculation and disruption of plasma membrane in the head region [37]. The present results showed immobility of sperms for Moringa oleifera L.and Sapindus trifoliatus L.seed extract.

\section{CONCLUSION}

The Moringa oleifera and Sapindus trifoliatus seed extract is hydrophilic in nature, mixes immediately with water and kills sperms within 15 seconds. Moringa oleifera L.and Sapindus trifoliatus L. possesses appreciable spermicidal potential, which was demonstrated by motility of human spermatozoa under in vitro condition and then confirmed by viability test. This may be explored as an effective constituent of vaginal contraceptives. The proposed spermicide can be a potent vaginal contraceptive and be formulated as cream. Further studies are needed to determine the precise mechanism of action of these plants on the sperm cell.

\section{ACKNOWLEDGEMENTS}

We should really thank Dr. Daule patil of Ahmednagar, for their laboratorial help. We also appreciate Dr. R. J. Barnabas Principal of Ahmednagar College and Principal, Head of Botany NAC and Science College, Ahmednagar for their continuous help rendered during this work.

\section{REFERENCES}

[1] Tocharus, C., Jeenapongsa, R., Teakthong, T., Smitasiri, Y. (2005). Effects of long-term treatment of Butea superb on sperm motility and concentration. Naresuan University Journal, 2014; 13(2): 11-17.

[2] Mathew, V., Bantwal, G. Male contraception. Indian Journal of Endocrinology and Metabolism, 2012; 16(6):910-917. doi:10.4103/2230-8210.102991.

[3] Waites, G. M. Development of methods of male contraception: impact of the world health organization tasks force. Fertile Sterile, 2003; 80 (1): 1-15.

[4] Singh, H. P., Singh, C. K., Singh, R. R. Effect of potash alum (aluminium potassium sulphate) on human semen and sperm. Indian J. Physiol. Pharmacol., 1998; 42:311-14.
[5] Hoffer, A.P., Agarwal, A., et al. Ultrastractural, fertility, and spermicidal studies with isomers and derivates of gossypol in male hamsters. Biology of Reproduction, 1987; 37: 909-924.

[6] Garg, S., Doncel, G., et al. Synergistic spermicidal activity of neem seed extract, reetha saponins and quinine hydrochloride. Contraception, 1994; 50 (2): 185-190.

[7] Khillare, B., Shrivastav, T.G. Spermicidal activity of Azadirachta indica (neem) leaf extract. Contraception, 2003; 68: 225-229.

[8] Bai, J.P., Shi, Y.L. Inhibition of $\mathrm{Ca} 2+$ channels in mouse spermatogenic cells by male antifertility compounds from Tripterygium wilfordii Hook. f. Contraception, 2002; 65(6): 441-445. [9] Delgado, N.M., Taboada Ramirez, J., et al. Effects of a purified fraction from Echeveria gibbiflora aqueous crude extract on guineapig spermatozoa. Phytotherapy Research, 1999; 13: 46-49.

[10] Reyes, R., Merchant-Larios, H., et al. Male contraception, IV: hypotonic like effect from Echeveria gibbiflora on human sperm. Archives of Andrology, 2002; 48: 443-449.

[11] Chakrabarti, K., Pal, S., et al. Sperm immobilization activity of Allium sativum L. and other plant extracts. Asian Journal of Andrology, 2003; 5 (2): 131-135.

[12] Lohiya, N.K., Kothari, L.K., et al. Human sperm immobilization effect of Carica papaya seed extracts: an in vitro study. Asian Journal of Andrology, 2000; 2: 103-109.

[13] Chattopadhyaya, D., Dungdungb, S.R., et al. A potent sperm motility inhibiting activity of bioflavonoids from an ethno medicine of Onge, Alstonia macrophylla Wall ex A. DC, leaf extract. Contraception, 2005; 71: 372-378.

[14] Sandhyakumary, K., Bobby, R.G., et al. Antifertility Effects of Ricinus communis (Linn) on Rats. Phytotherapy Research, 2003; 17: 508-511.

[15] Paul, D., Bera, B., et al. In vitro determination of the contraceptive spermicidal activity of a composite extract of Achyranthes aspera and Stephania hernandifolia on human semen. Contraception, 2006; 73(3): 284-288.

[16] Vasudeva, N., Vats, M. Anti-spermatogenic activity of ethanol extract of Dalbergia sisoo Roxb. stem bark. J. Aupunct. Meridian Stud., 2011; 4(2): 116-122.

[17] Nath, D., Sethi, N., Singh, R. K., Jain, A. K. Commonly used Indian abortifacient plants with special reference to their teratologic effect in rats. J. Ethnopharmacol., 1992; 36: 147-154.

[18] Ghasi, S., Nwobodo, E., Ofili, J. O. Hypocholesterolemic effects of crude extract of leaf of Moringa oleifera Lam. in high-fat diet fed Wistar rats. J. Ethnopharmacol., 2000; 69: 21-25.

[19] Lalas, S., Tsaknis, J. Extraction and identification of natural antioxidants from the seeds of Moringa oleifera tree variety of Malavi. J. Am. Oil. Chem. Soc., 2002; 79: 677-683.

[20] Padmarao, P., Acharya, B.M., Dennis, T.J. Pharmacognostic study on stem bark of Moringa oleifera Lam. Bull. of MedicoEthnoBotanical Res., 1996; 17: 141-151.

[21] Damke, E. J., Tsuzuki, et al. Spermicidal and anti-trichomonas viginalis activity of Brazilian Sapindus saponaria. BMC Complementary and Alternative Medicine, 2013; 13:196 DOI: $10.1186 / 1472-6882-13-196$.

[22] Natha, S., Choudhurya, M. D., Roychoudhurya, S., et al. Male contraceptive efficacy of Ricinus communis L. extract. J. of Ethnopharmacology, 2013; 149: 328-334.

[23] Kamboj, V. P. A review of Indian medicinal plants with interceptive activity. Indian J. Med. Res. 1988; 87:336-355.

[24] Remya, M., Sharma, R. C., et al. In vitro effects of Aegle marmelos on human sperm vitality. Biomedicine, 2009; 29(2):18385.

[25] Gaykar, B. M., Kulkarni, A. A., Borkar G. B. Ethnobotanical plants of tribal areas of Ahmednagar Dist. (M.S) Jour. Drug Res. Aurveda and Sidhha, 2006; XXVII (1-2): 73-61. 


\section{Indo Global Journal of Pharmaceutical Sciences, 2018; 8(1): 21-25}

[26] Zaneveld, L.J.D., Polakoski, K.L. Collection and physical examination of the ejaculate. In: Techniques of Human Andrology, Ed: E. S. E. Hafez. Elsevier/North Holland, 1977; 147-172.

[27] WHO. Collection and examination of human semen. Laboratory manual for the examination of human semen and semen cervical mucus interaction. Cambridge University Press: Cambridge, 1992; 312.

[28] Sander, F. V., Cramer, S. D. A practical method of testing the spermicidal action of chemical contraceptives. Human Fertil, 1941; 6:134-8.

[29] Ratnasooriya, W. D., Amarasekera, A. S., Perera, N. S., Premkumara, G. A. Sperm anti-motility properties of a seed extract of Abrus precatorius. J. Ethnopharmacol., 1991; 33:85-90.

[30] WHO Laboratory Manual for the Examination of Human Semen and Sperm-Cervical Mucus Interaction, 4th ed. New York: Cambridge University Press, 1999.

[31] Eliasson, R. Supravital staining of human spermatozoa. Fertility Sterility, 1977; 28: 1257.

[32] Jayendran, R. S., Vander, V., et al. Development of an assay to assess the functional integrity of the human sperm membrane and its relationship to other semen characteristics. J. of reproduction and fertility, 1994; 70:219-228.

[33] Mughal, M.H., Ali, G., Srivastava, P.S., Iqbal, M. Improvement of drumstick (Moringa pterygosperma Gaertn) - a unique source of food and medicine through tissue culture. Hamdard Med., 1999; 42: $37-42$.

[34] Obembe A. O., et al. The effect of aqueous seed extract of Moringa Oleifera on sperm count, motility and morphology in male albino wistar rats. Der Pharmacia Lettre, 2015; 7 (3):129-133.
[35] Sati, S.C., Sharma, A., et al. Chemical constituents and Bio activities of genus Sapindus. Int. Jour. Res. In Ayur. Pharmacy, 2011; 2(2): 403-409.

[36] Mdhluli, M.C., Vander Horst G. The effect of oleanolic acid on sperm motion characteristics and fertility of male Wistar rats. Laboratory Animals Ltd., 2002; 36: 432-437.

[37] Dhar, J. D., Bajpai, V. K., Shetty, B. S., Kamboj, V. P. () Morphological changes in human spermatozoa as examined under scanning electron microscope after in-vitro exposure to saponins isolated from Sapindus mukorossi. Contraception. 1989; 39(5): 563 568.

Indo Global Journal of Pharmaceutical Sciences( ISSN 22491023 ; UGC Journal No.: 44477; CODEN- IGJPAI; NLM ID: 101610675) indexed and abstracted in EMBASE(Elsevier), UGC Journal List, National Library of Medicine (NLM) Catalog, Elsevier( EMBASE), ResearchGate, Publons, CAS (ACS), Index Copernicus, Google Scholar and many more. For further details, visit http://iglobaljournal.com 